2 Stechschulte, D. J., Proc. Soc. expl Biol. Med., 131, 748-752 (1969). 3 Spira, D. T., Silverman, P. H., and Gaines, G., Immunology, 19, 759-766 (1970).

${ }^{4}$ Sheagren, J. N. and Monaco, A. P., Science, 164, 1423-1425 (1969).

5 Wolf, R. E., Clin. Immun. Immunopath., 2, 381-394 (1974).

- Cox, F. E. G., and Young, A. S., Parasitology, 59, 257-268 (1969).

7 Topley, E., Bruce-Chwatt, L. J., and Dorrell, J., J. Trop. Med. Hyg., 73, 1-8 (1970).

8 Ogilvie, B. M., and Jones, V. E., Parasitology, 57, 335-349 (1967).

\section{Evidence for oligomeric IgA production by peripheral rat lymph nodes}

A Distinctive characteristic of $\operatorname{IgA}$ is its polymorphic nature with regard to the molecular size. It occurs in secretions mostly as a dimer or tetramer ${ }^{1,2}$ while serum $\operatorname{IgA}$ has a polydisperse weight distribution in many species ${ }^{1}$. It is mostly monomeric in human serum (7S) (ref. 3), mostly polymeric in the mouse ${ }^{4}$ and in the $\operatorname{dog}^{5}$, but in both these and other species several molecular sizes occur in the blood ${ }^{1}$.

When extending studies on natural anti-hapten antibodies in the rat ${ }^{6}$ we made the unexpected finding that natural anti3-iodo-4-hydroxy-5-nitrophenylacetyl (NIP) of the thoracic duct lymph had sedimentation characteristics (9S-13S) similar to the secretory $\operatorname{IgA}$ antibodies that we could demonstrate in rabbit colostrum ${ }^{7}$ and to the oligomeric IgA produced by mouse spleen cultures ${ }^{8}$. Natural antibody in the blood serum of the same rats sedimented like 19S IgM. This finding prompted us to study sedimentation patterns of anti-NIP antibodies in the blood and the lymph of immunised rats.

Rats were immunised with $10 \mu \mathrm{g}$ NIP-SIII pneumococcal polysaccharide $^{8}$ or $500 \mu \mathrm{g}$ of NIP chicken globulin (CG) ${ }^{8}$ in complete Freund's adjuvant (CFA). As we wanted the antibody production to take place preferentially in the peripheral lymph nodes draining to the thoracic duct the antigen was injected into the hind foot pads. The rats were bled and cannulated (abdominal thoracic duct) 8-9 d after immunisation. Thoracic duct lymph samples wcrc clarified by spinning for one hour at $50,000 \mathrm{~g}$. The lymph and the serum samples were titrated with NIP-T 4 bacteriophages as described earlier ${ }^{9}$. They were centrifuged through a continuous and linear $5-20 \%$ sucrose gradient in $12 \mathrm{ml}$ tubes in rotor SW-41 Ti of a Beckman L 3-50 ultracentrifuge for $14 \mathrm{~h}(39,000$ r.p.m.). A total of 25 fractions were collected and titrated with NIP-T . Sedimentation constants $\left(\mathrm{S}_{20, \mathrm{w}}\right)$ were derived according to $\mathrm{McEwen}^{\mathbf{1 0}}$.

The predominant antibody peaks of the blood serum had sedimentation constants of 19S and 7S. A minor 9S component could usually be detected (Fig. 1a). Antibodies of the thoracic duct had major $19 \mathrm{~S}$ and $7 \mathrm{~S}$ fractions but they also had considerable $13 \mathrm{~S}$ and $11 \mathrm{~S}$ fractions (Fig. $1 b$ ); $9 \mathrm{~S}$ antibody could be seen as a distinct peak in some but not all lymph samples. We have found this phenomenon in all the 14 serum-lymph pairs studied so far.

In some experiments we incubated diluted lymph before centrifugation with rabbit anti-rat $\operatorname{IgA}$. Anti-IgA is known to

Table 1 Characteristics of the antibody classes that could be separated from the thoracic duct of immunised rats and lymph node culture fluids

\begin{tabular}{ccccc} 
Sedimentation & $\begin{array}{c}\text { Estimated } \\
\text { Stokes' } \\
\text { radius } \\
\text { constant }\end{array}$ & $\begin{array}{c}\text { Ig } \\
\text { class }\end{array}$ & $\begin{array}{c}\text { Determined } \\
\text { molecular } \\
\text { weight }\end{array}$ & $\begin{array}{c}\text { IgA polymer that } \\
\text { would come closest } \\
\text { to the observed } \\
\text { molecular weight } \\
\text { (see text) }\end{array}$ \\
13S & 107 & IgM & 860,000 & \\
$11 \mathrm{~S}$ & 91 & IgA & 515,000 & 520,000 \\
$9.4 \mathrm{~S}$ & 80 & IgA & 380,000 & 370,000 \\
\hline
\end{tabular}

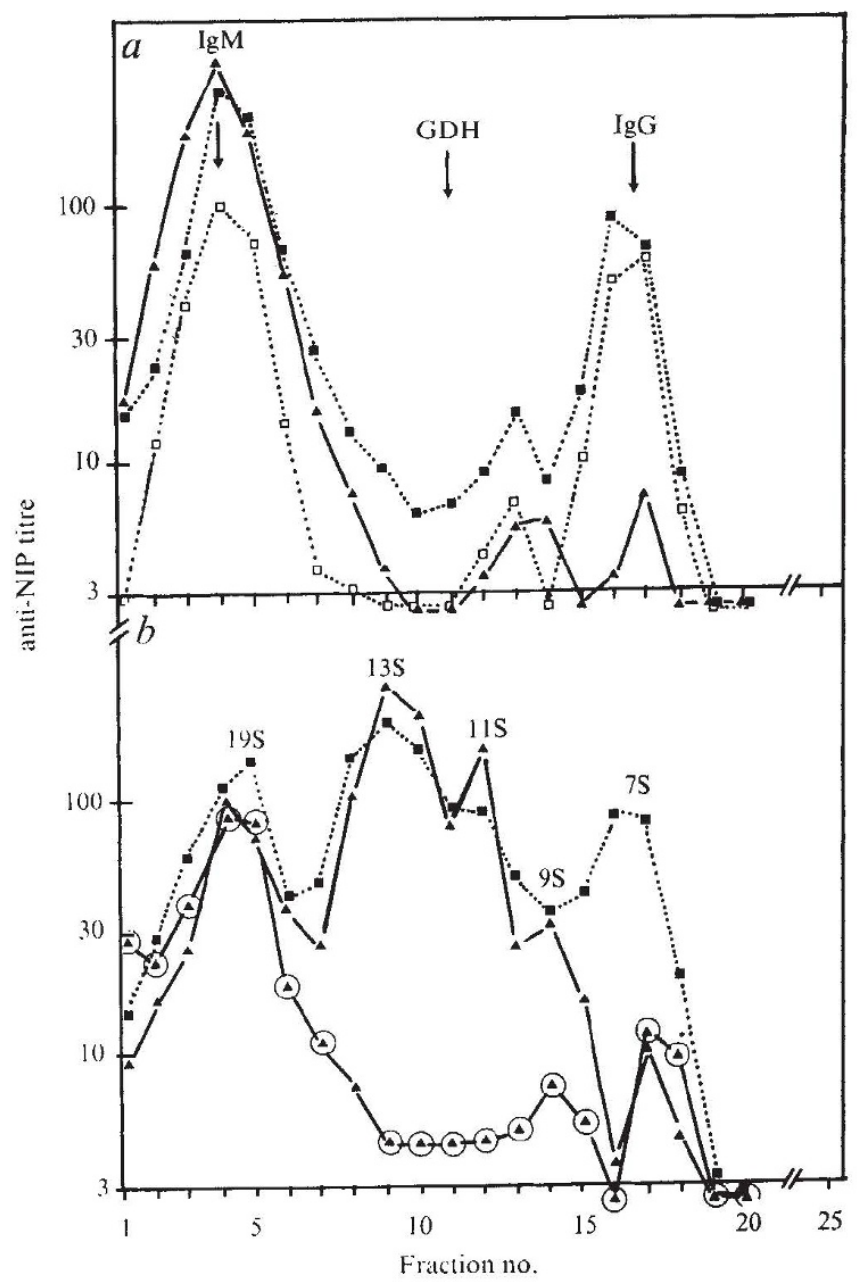

Fig. 1 Sedimentation pattern of anti-NIP, $a$, in the serum and, $b$, thoracic duct lymph of rats after immunisation with NIP-CG and NIP-SIII. - NIP-CG immunisation; ....., NIP-SHI/ immunisation; encircled triangles, sample mixed with anti-IgA. Different symbols indicate different rats. Rabbit anti-DNP and glutamate dehydrogenase (GDH) were used as reference

compounds, their maximum activity is indicated by arrows.

displace or eliminate IgA but not IgG or IgM antibodies in the sedimentation pattern ${ }^{8}$. Data in Fig. 1 show that the 9S, 11S and $13 \mathrm{~S}$ peaks were displaced by our anti-IgA and were thus very probably IgA.

The total IgA of several lymphs and sera was determined by the method of Mancini, Carbonara and Heremans ${ }^{11}$. We found that concentrations in the lymph fluid were 4-12 times higher than in the serum of the same animal. In the ultracentrifugation the IgA of the lymph fluids was fairly evenly distributed from the $7 \mathrm{~S}$ to $15 \mathrm{~S}$ fractions while the serum IgA was distributed from the $7 \mathrm{~S}$ to $11 \mathrm{~S}$ fractions.

The Stokes's radii of the four heaviest antibody fractions were determined by gel filtration according to Laurent and Killander ${ }^{12}$. They were calculated as means of two gel filtration runs, through a Sepharose 6 B column $(1.5 \times 79 \mathrm{~cm})$. Reference proteins in these runs included rat serum albumin, hyperimmune rabbit anti-DNP (IgG) and glutamate dehydrogenase. Their radii were assumed to be 35,51 and $60 \AA$ respectively ${ }^{13,14}$. The fractions from the gel filtration were rerun in ultracentrifugation. Molecular weights (Table 1) were calculated using the $\mathrm{S}_{20, w}$ values and the Stokes radii in the formula

$$
M=\left(6 \pi \eta_{20, w} N a_{20, w}\right) /\left(1-\bar{v} \rho_{20, w}\right)
$$

in which $\eta_{20, w}$ and $\rho_{20}, w$ are the viscosity and density of water at $20^{\circ} \mathrm{C}, N$ is Avogardo's constant and $a$ is Stokes's radius. The 
partial specific volume $(i)$ of oligomeric $\operatorname{IgA}$ was assumed to be 0.73 (ref. 15).

It is possible that 9S-13S IgA anti-NIP of the thoracic duct lymph mainly originates in the intestinal lymphoid tissue. For instance, plasmablasts generated in the regional lymph nodes may be transferred to the intestinal area and produce antibody there ${ }^{16}$. It was made unlikely, however, by the finding that when popliteal lymph nodes were removed from these rats and kept in organ cultures for $6 \mathrm{~h}$ without additional antigen they produced the same $9 \mathrm{~S}-13 \mathrm{~S}$ fractions which we found in the thoracic duct lymph. These again could be displaced by anti-IgA (Fig. 2).

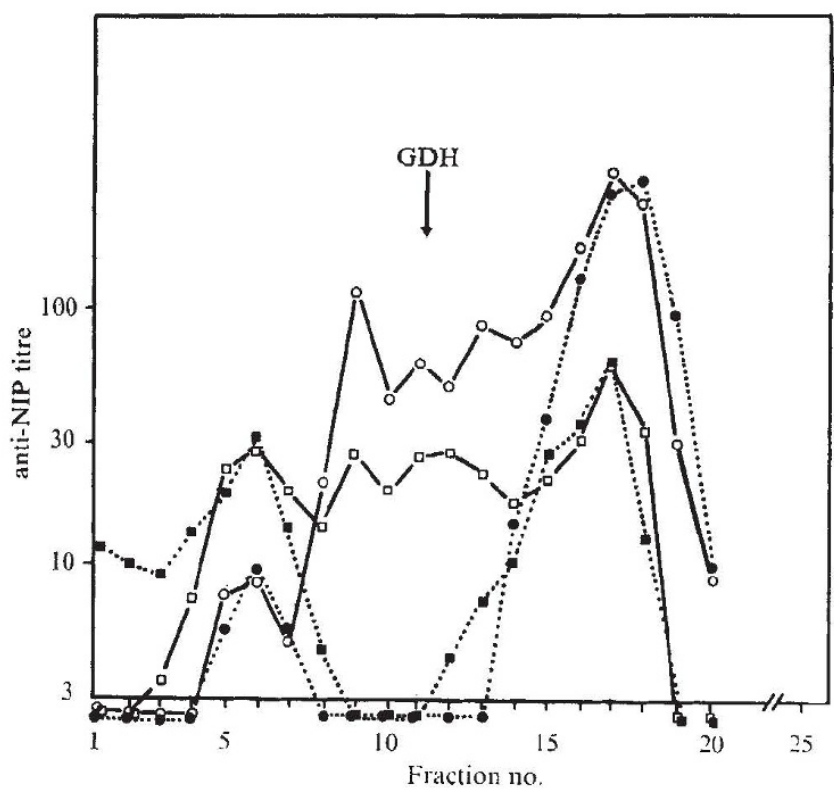

Fig. 2 Sedimentation pattern of anti-NIP activity produced by two organ cultures. Popliteal lymph nodes were removed 6 or $9 \mathrm{~d}$ after a foot pad immunisation (NIP-SIII) and $1 \mu \mathrm{l}$ pieces were cultured ${ }^{8}$ for $6 \mathrm{~h}([], \square)$ or $24 \mathrm{~h}(O, 0)$ without additional antigen. $\square$ and $O$, untreated samples; $\square$ and $\bigcirc$, samples mixed with anti-IgA, the rat represented by open squares is represented in the same way in Fig. 1.

Data in Fig. 2 are derived from the first two lymph node cultures we tested but we have studied five nodes from five rats. Four nodes produced the 9S-13S IgA antibody. One node produced little antibody, and all of it was 19S. These data suggest that at least some 9S-13S IgA anti-NIP was produced by regional lymph nodes of our rats.

We considered the possibility that the polymerisation had taken place outside the synthesising organs. The following facts, however, fail to support it. First, individual lymph samples maintained their sedimentation pattern through weeks of storage at $-20^{\circ} \mathrm{C}$. Second, centrifugation of lymph 15 min after it had left the thoracic duct showed a similar sedimentation pattern to lymph samples centrifuged later (rat no. 5 marked with closed squares in Fig. $1 b$ ). Third, in vitro synthesis of 9S-13S IgA antibody by lymph node fragments.

We believe that the different IgA antibody fractions represent different degrees of polymerisation. The molecular formulae of the three IgA fractions cannot be derived from our data but if we make the assumption that the molecular weight of the light chain, the $\alpha$ chain, J piece, secretory piece, and the carbohydrate content are the same in the rat IgA as those in man we find that our observed molecular weights would correspond reasonably well with the theoretical molecular weights of the following reconstructed human polymers; trimer + secretory piece $+\mathrm{J}$ piece (our $13 \mathrm{~S}$ IgA), a dimer + secretory piece $+\mathrm{J}$ piece (our 11S IgA) and dimer + J piece (our 9S IgA).

We conclude that non-intestinal lymphoid tissues produce polymerised IgA antibodies in immunised rats. This antibody can be demonstrated in the thoracic duct lymph and cultures of popliteal lymph nodes. It occurs in three main size classes with molecular weights of approximately $515,000,380,000$ and 280,000 . In the blood these antibodies, especially the two heavier classes, are either rapidly catabolised, reduced to small subunits, or secreted.

We thank Dr Ari Helenius for his advice and help in the determination of molecular weights and Mrs Maire Laakso for the cannulation of thoracic ducts. This work was supported by the Medical Research Council, Academy of Finland.

M. KAARTINEN

M. HURME

Department of Serology

O. MAKeLA

and Bacteriology,

University of Helsinki,

Haartmaninkatu 3,

Holsinki 29, Finland

Received June 27; revised September 3, 1974.

1 Tomasi, T. B., and Grey, H. M., Progr. Allergy, 16, 81-213 (1972).

2 Halpern, M. S., and Koshland, M. E., J. Immun., 111, 1653-1667 (1973).

${ }^{3}$ Heremans, J. F., Heremans, M.Th., and Schulze, H. E., Clin. chim. Acta, 4, 96-102 (1959).

4 Grey, H. M., Sher, A., and Shaltin, N., J. Immun., 105, 75-84 (1970).

5 Vaerman, J.-P., Heremans, J. F., Immunology, 18, 27-38 (1970).

6 Jormalainen, S., and Mäkelä, O., Eur.J.Immun., 1, 471-478(1971)

7 Mäkelä, O., Kostiainen, E., Koponen, T., and Ruoslahti, E., in Killander Nobel Symposium 3: Gamma Globulins. Structure and control of biosynthesis, 505-516 (Almqvist and Wiksell, Stockholm, 1967).

8 Nakamura, I., Ray, A., and Mäkelä, O., J. exp. Med., 138, 973-988 (1973).

9 Mäkelä, O., Immunology, 10, 81-86 (1966).

10 McEwen, C. R., Analyt. Biochem., 20, 114-149 (1967).

11 Mancini, G., Carbonara, A. O., and Heremans, J. F., Immunochemistry, 2, 235-254 (1965).

12 Laurent, T. C., and Killander, J., J. Chromatogr., 14, 317-330 (1964).

${ }^{13}$ Simons, K., Helenius, A., and Garoff, H., J. molec. Biol., 80, 119-133 (1973).

14 Tanford, Ch., Nozaki, Y., Reynolds, J. A., and Makino, S., Biochemistry (in the press).

15 Reynolds, H. Y., and Johnson, J. S., Biochemistry, 10, 2821-2827 (1971).

${ }^{16}$ Hall, J. G., Parry, D. M., and Smith, M. E., Cell Tissue Kinet., 5, 269-281 (1972).

\section{Antigenic inhibition of cell-mediated cytotoxicity against tumour cells}

THERE is now abundant evidence that tumour cells express new surface antigens (tumour-associated antigens, TAA) ${ }^{1}$. In many tumour models, cell-mediated immunity directed against TAA has been demonstrated in vitro ${ }^{2}$. Serum from tumour-bearing individuals has been shown to inhibit specifically cell-mediated immune responses (CMI) to the tumour target cells in vitro ${ }^{3}$, and this phenomenon may explain the paradoxical coexistence of a growing tumour and an immune response directed against the tumour. Both immune complexes of TAA with antibody ${ }^{4,5}$, and soluble TAA alone ${ }^{6}$, have been implicated as inhibitors in these sera.

In most studies, however, neither the nature of the effector cell nor the mechanism of inhibition, have been well characterised. CMI against tumours induced in mice by murine sarcoma virus (MuSV), which was measured in a microcytotoxicity assay (MCA), and in which both $\mathrm{T}$ and non- $\mathrm{T}$ effector cells were cytotoxic, was inhibited by progressor serum and by soluble TAA $^{7}$, In concurrent studies with a short term ${ }^{51} \mathrm{Cr}$ release assay, in which only $\mathrm{T}$ cells were cytotoxic, there was no inhibition. In antiallogeneic CMI, cytotoxicity by $T$ cells 